\title{
Smart Street Lighting Detecting Vehicle and Pedestrian Movement Aiming for Sustainable Bhutan
}

\author{
Karchung, Zepa Tenzin, Sonam Tenzin, Sonam Tobgay, Dorji Gyeltshen
}

\begin{abstract}
An energy crisis is global issue nowadays. Bhutan however, does not realize it being blessed with good geographical and demographical diversity. It is high time that Bhutan realize the need of energy conservation technique. The electrical energy is wasted unnecessarily which starts from keeping the mobile charger plugged in the socket when not in use to lamps keeping ON in streets throughout day and night. People don't seem to care but monitoring it for better conservation benefit has become crucial in underdeveloped countries like Bhutan whose source of energy is limited to hydropower only. Wind and solar generations are feasible but the energy cost per unit would be very high due to high initial cost. A case study conducted within the college campus revealed tremendous savings a college can make just by replacing conventional compact fluorescent lamp (CFL) with light emitting diode (LED). Therefore, the best option for Bhutan and Bhutanese people is to take better care of the existing energy sources and use it judiciously. This paper proposes a method to monitor and control the street/compound lighting in a smarter way. The two types of sensors are employed. The light dependent resistor $(L D R)$ is used to monitor the intensity or brightness of surrounding and passive infrared (PIR) sensor is employed for detecting infrared source. The sensor output is processed and monitored by the PIC16F877A microcontroller. Moreover, the incandescent lamp and the compact fluorescent lamp will be replaced by LED lamps. The project aims to reduce power consumption in Bhutan through proposer control of street/compound lighting so as to have better economy of the country by exporting more unit of energy to neighboring country.
\end{abstract}

Keywords: smart street light PIC16F877A microcontroller, Proteus software, light dependent resistor, passive infrared sensor

\section{INTRODUCTION}

$\mathrm{T}$ he smart street lighting; through the use of hardware and software may prove more advantageous in long run because the power demand keeps on increasing but the generation is getting stagnant. The costs of energy will shoot-up at the rate of the demand. The major problem at

Revised Manuscript Received on February 25, 2020.

* Correspondence Author

Karchung*, Lecturer, Electrical Engineering Department, Jigme Namgyel Engineering College, Dewathang, Bhutan. Email: karchung.jnec@rub.edu.bt

Zepa Tenzin, Sonam Tenzin Sonam Tobgay and Dorji Gyeltshen, Electrical Engineering Department, Jigme Namgyel Engineering College, Dewathang, Bhutan.

(C) The Authors. Published by Blue Eyes Intelligence Engineering and Sciences Publication (BEIESP). This is an open access article under the CC BY-NC-ND license (http://creativecommons.org/licenses/by-nc-nd/4.0/) present irrespective of size of country is revenue loss incurred due to energy wastage in street lighting systems [1]. It is affecting country's economy. In the urban centers, the most challenging issue is with the energy management because of their complexity and their pivotal role [2]. The street lightings are provided to offer safe and comfortable environment for drivers and pedestrians during night and foggy weather [1], [2]. However, at present, street/compound lamps are found to be illumined at all times irrespective of time and presence or absence of pedestrian or vehicle movement. It is simply a wastage of energy [3]-[6]. Furthermore, the lamps are found to be illuminated with full brightness at midnight or even in daylight most of the times [7]. Although, completely resolving energy wastage is not easy [1], it can be minimized to certain extent by employing so called efficient and smart lighting system [8]. The efficiency can be achieved by replacing conventional incandescent and fluorescent lamps by LEDs, and the lightings can be retrofitted to make smart by providing automatic monitoring and control algorithm. This can adapt quickly to environmental change by use of hardware and software. The former guarantees a lower level of energy consumption, while latter maximizes output and efficacy of lighting system.

Various research articles are published in the web with different methods and ideas to tackle common issue. One way is to employ sensors to automatically detect intensity or light and presence of vehicle or human moving either using microcontroller, Arduino, raspberry PI etc. [3]-[5], [7], [9]. The same can be achieved web-based algorithm without a need of any microcomputers [10], [11]. IoT would also be a good choice for tackling the issue which is anticipated to improve performance while reducing the investment on monitoring and management [12]. However, cost, lifespan, durability, technology, feasibility and reliability are some most important factor to consider while planning to design such system. Geographical location, classification of city, and size of system also affects considerably on the system design. For instance, developing web-based control algorithm in small educational institution like ours would just be a wastage of time and money.

One simple energy saving tip is to shift our attention to efficient LED technology. LEDs are widely used product nowadays which is prominent on street or residential/commercial compound [4], [13]. The electricity consumption reduction of $36.20 \%$ to $43.70 \%$ can be achieved by use of LED lamps [14]. 
Some of the promising characteristics like higher efficacy (lumens per watt), compact size, longer lifespan, and robustness [15] are making superior to any lighting systems available in market. LED can also have stand-alone system powered directly by renewable sources like wind and solar without the need of grid connection or complicated protection circuits [15].

Furthermore, it can be modified in its design easily to enhance aesthetic view (increase customer attraction) in addition to offering slimmer design compared to conventional metal halide arc lamps.

Bhutan having blessed with steep flowing rivers have even bigger potential to harness electrical energy. Hydropower is therefore, primary source of country's economy by exporting the surplus energy to neighboring country of India. If internal energy usage can be minimized, the benefit is only to municipality or the firm but also helps in improving the country's revenue by increasing the export. Jigme Namgyel Engineering College under Royal University of Bhutan being one of the premier engineering collages has role to take in this energy saving move.

A short survey was carried out within the college campus to study the energy and cost saving it can be achieved if conventional existing CFLs are replaced with modern LEDs. Based on the survey results, the retrofit measure is proposed in this paper. This paper proposes a cheap, maintainable, reprogrammable, and efficient energy efficient yet intelligent street/compound lighting system using LED lamps. Basically, two sensors are employed: light dependent resistor (LDR) and passive infrared (PIR) sensors to detect intensity of light and presence of infrared on the road/street, respectively. The circuit was designed and simulated in Proteus software. The heart of this system is PIC16F877A microcontroller. The control program is developed in MikroC compiler. The prototype is developed in the laboratory and implemented for one of the compound lamps in the college campus.

\section{METHODOLOGY}

The street lighting can be considered smart only if there are automatic control capabilities of the lamp. It includes illuminating when the darkness approaches and make smart decision to how long the lamps will be kept illuminated.

In this proposed method, the PIC16F877A is the employed to take central control decision. Light Dependent Resistor (LDR) senses the light intensity as human eye. It will detect the day light intensity and the extent of darkness at which the streets light is to be illuminated is programmed in microcontroller, using MikroC compiler and dumped in the microcontroller using PICKIT2 programmer. However, to have better energy management, the lamps are to be lit continuously only until certain time (until 10 PM in our case because it is silence hour in the college and so students are not supposed to move around). After that the MCU will disable LDR pin and enable to the PIR sensor pin using the real time clock. Vice versa happens the day returns. The vehicle and the pedestrian movement are sensed by PIR sensor. As the aforementioned sensor output goes high, the microcontroller will actuate the relay to switch ON the main supply to the street light. The configuration is such that the single-phase supply to the street lamp is divided into two; one is rectified using bridge diode rectifier, filtered and is regulated to $12 \mathrm{~V}$ DC for the relay and is further regulated to
$5 \mathrm{~V}$ DC for the microcontroller supply source. The other source is directly connected to the street lamp via relay actuated by $12 \mathrm{~V}$ DC source.

An Oscillator circuit is used to provide a microcontroller with a clock. A clock is needed so that the microcontroller can execute a program (Ibrahim, 2006).

PIC controllers have built-in oscillator circuits. It needs an external crystal that decides the operating frequency of the microcontroller. It is installed within the microcontroller and connected to the OSC1 and OSC2 pins.

\section{A. Passive Infrared (PIR) sensor}

A PIR sensor is a passive electronic device which measures infrared radiation emitted from the objects that has capability to generate heat.

The sensor has capability to not just to detect the radiation itself but also the change in condition. The change in the amount of infrared radiation falling on the face causes the corresponding change in the voltage generated which is measured by on-board amplifier.

When the PIR sensor detects the vehicle or pedestrian entering the road/street, its output pin goes high which can be understood by the MCU and thus the lamp is turned ON. The lamp remains in this state unless the sensor output pin goes low which depicts that the infrared source has crossed the sensing range [9]. The lamp thus turns off after certain delay based on the sensing range of sensor for the pedestrian to enter the next sensor zone to have continuous illumination. as long as the person or vehicle is within its sensing range. The PIR sensor device is shown in Fig. 1.

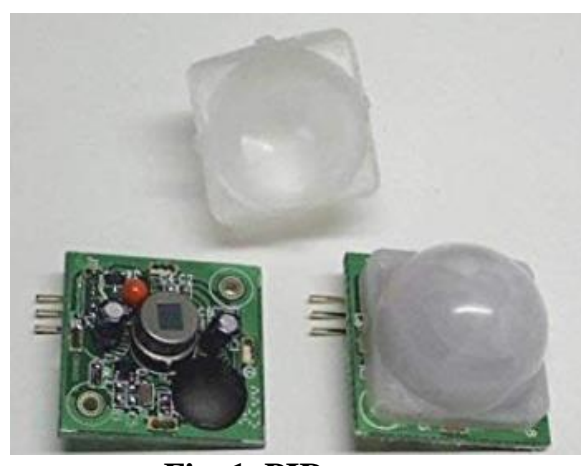

Fig. 1. PIR sensor

KC7786 PIR sensor is considered in this project. A small sized with inbuilt amplifier, regulator and logic circuit has detection range of $5 \mathrm{~m}$. As shown in Fig. 1, the PIR sensor has three pins, first two pins are for power supply (12 V DC) and third pin for data output. The output pin is to be connected to a microcontroller pin to detect any changes.

\section{B. Light Dependent Resistor (LDR)}

The LDR, or sometimes called photocell is a variable resistor with light affinity. Its resistance is inversely proportional incident light intensity. The resistance of photo resistor would reach several mega ohms (M $\Omega$ ) when placed in dark environment, while in the light, the resistance drops to a few hundred ohms.

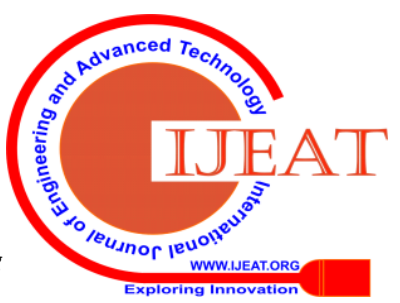



electrons jump into the conduction band when incident light on photoresistor exceeds certain frequency. Thus, resulting in the free electrons (and their hole pair) conduct electricity, thereby lowering resistance of photoresistor. The LDR is shown in Fig. 2.

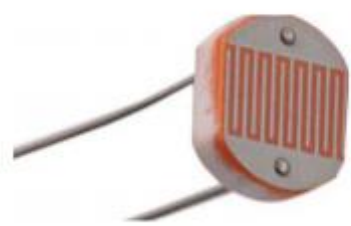

Fig. 2. LDR

\section{PIC16F877A Microcontroller}

Programmable Interface Controllers (PIC) MCU; developed by Microchip technology offer ease in programming, widely available, easy interfacing capability with other peripherals, cheap, reprogramming capability with flesh memory [16]. The Harvard architecture based PIC MCU are, therefore, extensively used for industrial purposes. PIC MCUs are compatible to different software that are available in market. However, while programming for this MCUs, generally integrated development environment (IDE), compiler and integrated programming environment (IPE) are required. The IDE is the environment in which programming takes place while compiler converts developed program into HEX files (MCU readable files). Similarly, IPE dumps our converted HEX file to PIC MCU.

An 8-bit, 40 pin PIC16F877A is chosen for this project due to available online tutorials and also one of the widely used MCU. It is a powerful with 200 nanosecond instruction execution time yet easy-to-program CMOS Flash-based MCU. The some of the special features of this MCU are: 256 bytes of EEPROM data memory, contains ICD, 8 channels of 10-bit A/D converters, two comparators, two capture/PWM/comparator, SPI, I2C and USART.

The 'mikroC Pro for PIC' was used for programming, compiling and debugging the MCU program. It is powerful software with capability to program, compile, and debug in one environment. It also offers a unique mechanism to easily use libraries in the project. Moreover, third-party libraries also can be installed and easily be managed by library manager without having to use numerous include directives. Similarly, the program is downloaded/burned to PIC using PICKIT2 programmer hardware.

\section{CIRCUIT SIMULATION IN PROTEUS}

The circuit for power supply system of $5 \mathrm{~V}$ for microcontroller and $12 \mathrm{~V}$ for relay, and overall circuit for the system using PIC16F877A are simulated separately in Proteus software. By using circuit component values of the system from simulation, hardware prototype was developed.

\section{A. Power Supply Unit}

The power supply unit is simulated from $230 \mathrm{~V}, 50 \mathrm{~Hz}$ commercial single-phase supply with two outputs of 5V DC for microcontroller input and 12V DC for relay input. A single-phase, center-tap transformer of $230 \mathrm{~V} / 12 \mathrm{~V}$ is used to step-down the voltage to working voltage. Four IN2007 diodes-bridge rectifier is used to convert AC quantities to the
This phenomenon happens due to the fact that valence

equivalent DC output. There is requirement of three filter capacitors as shown in power circuit model in Fig. 3. The value of the filter capacitor, $C_{1}$ of filter is given by equation

$$
\frac{I_{d c}}{2 \pi f C_{1}} \leq \mathrm{V}_{\mathrm{v}_{(\mathrm{PP})}}
$$

Where, $V_{v(p p)}$ is the peak-to-peak ripple voltage, $I_{d c}$ is the DC current, and, $\mathrm{f}$ is the supply frequency.

By substituting the design parameters in the Eq. (1), filter capacitor of value $43.844 \mu F$ or preferably more is required to be selected. The capacitor value of $470 \mu F$ is therefore chosen for this project. The other capacitor values for $C_{2}$ and $C_{3}$ are chosen as $0.01 \mu F$ based on the requirement in the datasheet for voltage regulator LM7812 and LM7805. Filters are used to remove the AC ripples present in the DC signal. Two voltage regulators are used to obtain fixed voltages of $5 \mathrm{~V}$ and $12 \mathrm{~V}$ respectively.

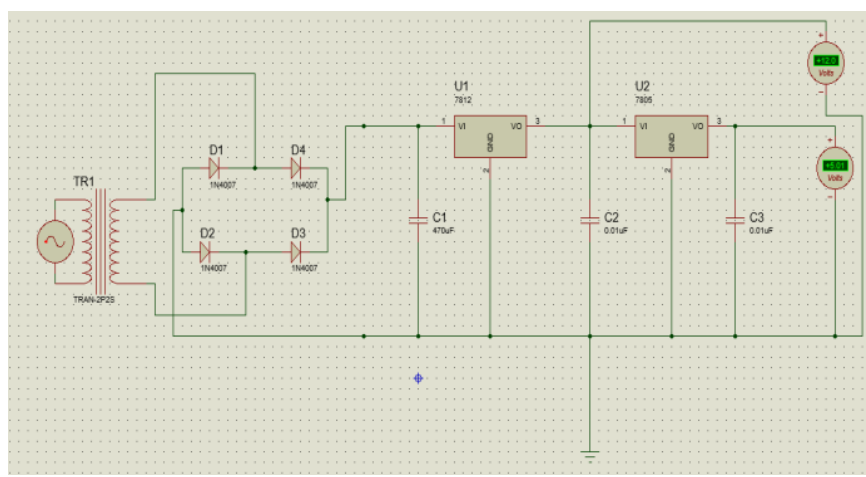

Fig. 3. Power Supply circuit

\section{B. Microcontroller Interfacing}

PIC MCU have built-in oscillator circuits. It needs an external crystal that decides the operating frequency of the microcontroller. It is installed within the microcontroller and connected to the OSC1 and OSC2 pins. This is evident from simulation model of proposed system presented in Fig. 4. On the MCU, two input pins are defined for configuring to the sensor outputs and an output pin to control relay action.

The LDR circuit is connected to pin ADC0 of the MCU. The analog voltage output from LDR $(0-3 \mathrm{~V})$ is converted to digital equivalent using in-built ADC module in MCU. Similarly, the PIR sensor is connected to the pin PD0. Since the output pin of PIR sensor goes to $0 \mathrm{~V}$ when control signal is set, the MCU pin must be pulled up (Connected to $+V_{D D}$ through a $10 \mathrm{k} \Omega$ ) to detect changes when sensor senses the intruder. The proposed circuit simulated in Proteus software is shown in Fig. 4.

The SKU-00535 relay with $12 \mathrm{~V}$ coil supply and $10 \mathrm{~A}$, $250 \mathrm{~V}$ AC control is used. The relay requires $30 \mathrm{~A}$ of current for relay to get activated but from the data sheet of PIC16F877A, the maximum output current at any I/O pin is only $25 \mathrm{~mA}$. This current is not enough to drive relay. Therefore, NPN transistor (BC547) is used driven into saturation region to use as switch to drive the relay. A back-EMF suppression diode (1N4007) is used across the relay contacts in order to prevent damage to the transistor when the relay operates. 
The transistor is turned ON (driven into saturation region) when a high logic is written on the MCU output pin. Contrarily, the transistor is switched off when logic low is written.

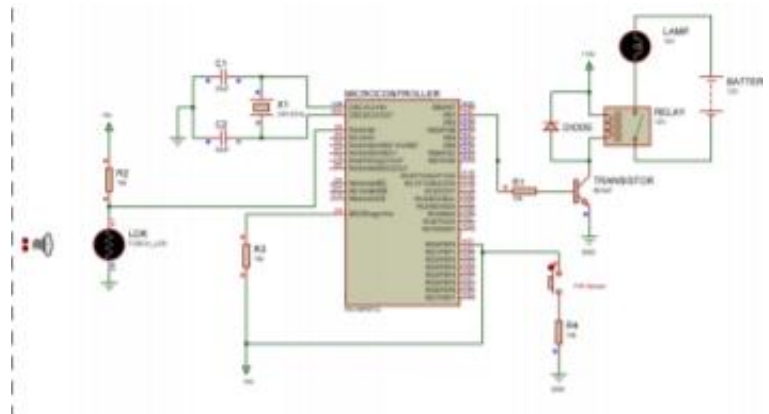

Fig. 4. Overall Circuit

The transistor's maximum collector current $I_{c(\max )}$ must be greater than the load current $I_{L}$. The load current is given by equation:

$$
I_{L}=\frac{V_{s}}{R_{L_{s}}}
$$

Where, $V_{S}$ is supply voltage and $R_{L}$ is load resistance. Since DC current gain ( $h_{f e}$ ) of BC547 is 110 , and the maximum collector current is $I_{C}=50 \mathrm{~mA}$, current to base of $\mathrm{BC} 47$ is given by equation below

$$
I_{C}=\frac{V_{c c}-V_{\text {out }}}{R_{c}}=h_{f e} \frac{V_{\text {in }}-V_{f}}{R_{B}}
$$

The value of $R_{B}$ obtained is thus $9.46 \mathrm{k} \Omega$. The resistance value of $10 \mathrm{k} \Omega$ is selected for this project. Here, $V_{f}$ is the "turn-on" voltage of the transistor's base-emitter junction (i.e. $V_{f}=0.5$ to $0.7 \mathrm{~V}$ ).

The single-phase commercial supply to the lamp is controlled by the relay. In the simulation, a fixed DC supply is chosen for simulation to drive DC lamp.

\section{ENERGY AUDIT IN COLLEGE CAMPUS (CASE STUDY)}

A case study has been conducted within the Jigme Namgyel Engineering College (JNEC) campus as presented in Tab. I. It showed that nearly Nu. 5,500 (\$81) can be saved monthly just for electricity consumptions by retrofit applied to street and compound lightings within the campus.

\begin{tabular}{|c|c|c|c|c|c|c|}
\hline \multicolumn{7}{|c|}{ Present energy consumed and monthly Bill in the JNEC compound } \\
\hline Lamps & Numbers & $\begin{array}{l}\text { Rating } \\
\text { (watts) }\end{array}$ & $\begin{array}{c}\text { Hours } \\
\text { used } \\
\text { (Hours) }\end{array}$ & $\begin{array}{c}\text { Energy } \\
\text { consumed } \\
\text { (kWh) }\end{array}$ & $\begin{array}{c}\text { Energy } \\
\text { consumed in a } \\
\text { month (kWh) }\end{array}$ & $\begin{array}{l}\text { Monthly } \\
\text { Bill (Nu.) }\end{array}$ \\
\hline CFL-street & 61 & 85 & 12 & 62.22 & 1866.6 & 4770.838 \\
\hline CFL-compound & 53 & 27 & 12 & 17.172 & 515.16 & 1486.8388 \\
\hline \multicolumn{6}{|c|}{ Total monthly bill } & 6257.6768 \\
\hline \multicolumn{7}{|c|}{ Total energy consumed and Monthly Bill if all the CFLs are replaced by LED lamps } \\
\hline Lamps & Numbers & $\begin{array}{l}\text { Rating } \\
\text { (watts) }\end{array}$ & $\begin{array}{c}\text { Hours } \\
\text { used } \\
\text { (Hours) }\end{array}$ & $\begin{array}{c}\text { Energy } \\
\text { consumed } \\
\text { (kWh) }\end{array}$ & $\begin{array}{c}\text { Energy } \\
\text { consumed in a } \\
\text { month (kWh) }\end{array}$ & $\begin{array}{l}\text { Monthly } \\
\text { Bill (Nu.) }\end{array}$ \\
\hline LED-street & 61 & 15 & 6 & 5.49 & 164.7 & 635.221 \\
\hline LED- compound & 53 & 11 & 6 & 3.498 & 104.94 & 490.0042 \\
\hline \multicolumn{6}{|c|}{ Total Monthly Bill } & 1125.2252 \\
\hline \multicolumn{6}{|c|}{ Initial Cost } & \\
\hline \multicolumn{5}{|c|}{ Initial cost of CFL( life- 8,000)-street } & $760 * 61$ & 46,360 \\
\hline \multicolumn{5}{|c|}{ Initial cost of CFL ( life- 8,000 )-compound } & $355 * 53$ & 18,815 \\
\hline \multicolumn{5}{|c|}{ Initial cost of LED (life - 50,000 hrs)-street } & $3400 * 61$ & 207,400 \\
\hline \multirow{2}{*}{\multicolumn{6}{|c|}{ Initial cost of LED (life - $50,000 \mathrm{hrs)-} \mathrm{compound}$}} & 159,000 \\
\hline & & & & & & 20,000 \\
\hline \multicolumn{6}{|c|}{ Monthly saving from bills } & 5132.45 \\
\hline
\end{tabular}

Table- I. The energy audit report for JNEC

Payback period according to [17] is defined as "the time in which the initial cash outflow of an investment is expected to be recovered from the cash inflows generated by the investment". It is one of the simplest investment appraisal techniques. If we calculate the life of LED based on the datasheet provided by the company, it will last for nearly 23 years if it is used 6 hours in a day. This may not be reasonable in real life so, considering the cash flow period of 5 years, the payback period calculated using formula

$$
\begin{aligned}
& \text { Payback Period }=\frac{\text { Initial investment }}{\text { Cash inflow per period }} \\
& =1.16 \text { years } \approx 14 \text { months }
\end{aligned}
$$

Even if we take the worst case with cash flow period of 5 years, the payback period is only 14 months which proves that proposed project will be helpful to government, agencies or private institutions. Once the payback period is reached, the saving obtained from the electricity bills will be the cost saving. Considering 5 years as the cash inflow period and 1.16 year as the payback period, the saving will be (5-1.16) $\mathrm{x}$ $5132.45=\mathrm{Nu} .19,708.60(\$ 290)$ until the LED lamps have to be replaced.

\section{ANALYSIS AND IMPLEMENTATION}

The prototype developed in the laboratory is presented in Fig. 5. The Fig 5 (a) shows the power supply hardware, while Fig. 5(b) shows the overall hardware prototype with MCU. 


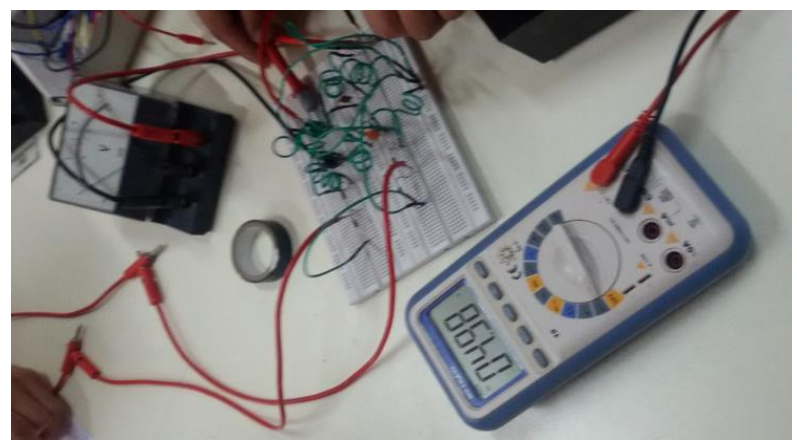

(a)

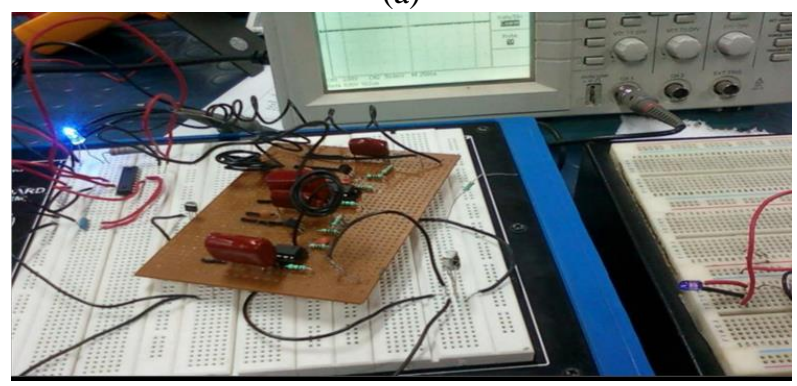

(b)

Fig. 5. Proposed Prototype developed in laboratory

The prototype assembly was installed and tested on one of the compound lighting at the roadside in front of Electrical Engineering Block, JNEC. The setup is presented in Fig 6. As it is shown in the figure, the PIR sensor is mounted on the neck of lamp post to avoid the reach of human to prevent from damaging.

The control unit is placed in the cemented cabinet on the basement to protect from rain, humidity or sunlight and locked to prevent damaging and stealing. The LDR sensor is also mounted at the basement but is exposed to the outside atmosphere by ventilating the cabinet with transparent glass window.

It was observed that the assembly sufficed the objective of the project. The sensor senses the movement at the angle of $60^{\circ}$ on its face and the light lasts for 30 seconds once the person has crossed the sensor.

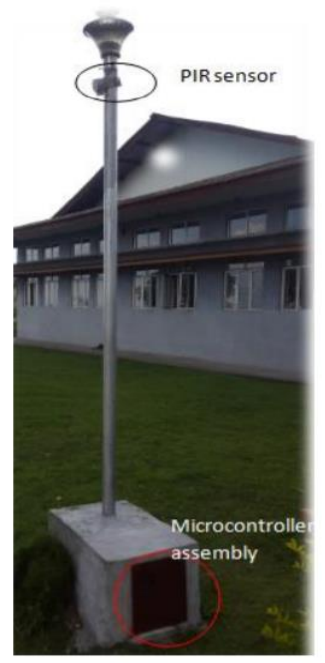

Fig. 6. Implementation of proposed method

\section{CONCLUSION}

The simple energy auditing done in the college campus recommended the existing CFLs or mercury/sodium vapor lamps to be replaced by the modern energy efficient LEDs and to have automatic control of lamps to turn on/off based on requirements. Based on these findings, a complete working prototype of smart street/compound lighting system using PIC microcontroller was developed in laboratory and tested successfully in one of the compound lamps in college campus. The system was initially modeled and simulated in Proteus software. The main advantage of the present system is power saving. It has low initial cost require only for designing and installation. One design can be duplicated for as many control circuits as we need and the central control board will do overall sequencing tasks. Hence, such systems are useful to the government, colleges, schools or any private sectors to reduce the utilization of power. This type of retrofit techniques can also help in peak load shaving by turning off unnecessary lamps.

The second recommendation to replace the conventional lamps with LEDS showed good profit margin with the payback period of little more than a year. This kind of retrofit techniques will become famous in the municipalities and in commercial areas due to simple control circuit which avoids constant supervision and offers greater flexibility in design.

\section{ACKNOWLEDGMENT}

This work is part of final year project supported by Jigme Namgyel Engineering College, Royal University of Bhutan. The authors acknowledge 2017 batch Diploma student group members: Thinley Wangchuk, Ugyen Choeda, and Ugyen Tashi for their valuable contribution in this project.

\section{REFERENCES}

1. P. Mohandas, J. S. A. Dhanaraj, and X.-Z. Gao, "Artificial Neural Network based Smart and Energy Efficient Street Lighting System: A Case Study for Residential area in Hosur," Sustain. Cities Soc., vol. 48, p. 101499, Jul. 2019, doi: 10.1016/j.scs.2019.101499.

2. R. Carli, M. Dotoli, and E. Cianci, "An optimization tool for energy efficiency of street lighting systems in smart cities," 20th IFAC World Congr., vol. 50, no. 1, pp. 14460-14464, Jul. 2017, doi: 10.1016/j.ifacol.2017.08.2292.

3. S. A. Bhosale and T. Ankalkote, "Modern Street Lighting System with Intensity Control based on Vehicle Movements and Atmospheric Conditions using Zigbee," in 2018 International Conference on Information , Communication, Engineering and Technology (ICICET), 2018, pp. 1-4, doi: 10.1109/ICICET.2018.8533817.

4. M. A. K. Riyaz, S. ArunJeyakumar, M. A. H. Sharik, and A. Tamilarasi, "Graphene coated LED based automatic street lighting system using Arduino microcontroller," in 2017 IEEE International Conference on Power, Control, Signals and Instrumentation Engineering (ICPCSI), 2017, pp. 1555-1560, doi: 10.1109/ICPCSI.2017.8391972.

5. D. Sunehra and S. Rajasri, "Automatic street light control system using wireless sensor networks," in 2017 IEEE International Conference on Power, Control, Signals and Instrumentation Engineering (ICPCSI), 2017, pp. 2915-2919, doi: 10.1109/ICPCSI.2017.8392257.

6. H. Ahmad, K. Naseer, M. Asif, and M. F. Alam, "Smart Street Light System Powered by Footsteps," in 2019 International Conference on Green and Human Information Technology (ICGHIT), 2019, pp. 122-124, doi: 10.1109/ICGHIT.2019.00036.

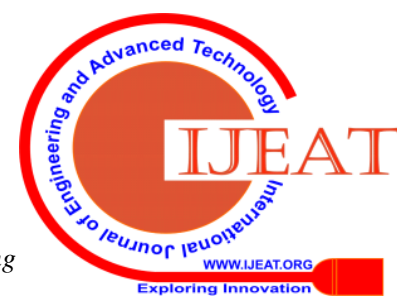


7. G. Das, "An intelligent method for optimizing the street-light-intensity," in 2018 2nd International Conference on Electronics, Materials Engineering Nano-Technology (IEMENTech), 2018, pp. 1-3, doi: 10.1109/IEMENTECH.2018.8464755.

8. E. Petritoli, F. Leccese, S. Pizzuti, and F. Pieroni, "Smart lighting as basic building block of smart city: An energy performance comparative case study," Measurement, vol. 136, pp. 466-477, Mar. 2019, doi: 10.1016/j.measurement.2018.12.095.

9. O. Singh and T. S. Sisodia, "Solar LED street light system with automatic scheme," in 2017 International Conference on Energy, Communication, Data Analytics and Soft Computing (ICECDS), 2017, pp. 3415-3419, doi: 10.1109/ICECDS.2017.8390094.

10. S. PRIYANKA, T. U. LAKSHMI, and S. S. SAKTHY, "Web -Based Street Light System," in 2019 3rd International Conference on Computing and Communications Technologies (ICCCT), 2019, pp. 159-162, doi: 10.1109/ICCCT2.2019.8824931.

11. D. Jin et al., "Smart street lighting system: A platform for innovative smart city applications and a new frontier for cyber-security," Electr. J., vol. 29, no. 10, pp. 28-35, Dec. 2016, doi: 10.1016/j.tej.2016.11.011.

12. M. Y. Mukta, M. A. Rahman, A. T. Asyhari, and M. Z. Alam Bhuiyan, "IoT for energy efficient green highway lighting systems: Challenges and issues," J. Netw. Comput. Appl., p. 102575, Feb. 2020, doi: 10.1016/j.jnca.2020.102575.

13. K. S. Sheela and S. Padmadevi, "Survey on Street Lighting System Based On Vehicle Movements," vol. 3, no. 2, p. 6, 2007.

14. M. Pagden, K. Ngahane, and Md. S. R. Amin, "Changing the colour of night on urban streets - LED vs. part-night lighting system," Socioecon. Plann. Sci., vol. 69, p. 100692, Mar. 2020, doi: 10.1016/j.seps.2019.02.007.

15. M. D. Vijay, K. Shah, G. Bhuvaneswari, and B. Singh, "LED based street lighting with automatic intensity control using solar PV," in 2015 IEEE IAS Joint Industrial and Commercial Power Systems / Petroleum and Chemical Industry Conference (ICPSPCIC), 2015, pp. 197-202, doi: 10.1109/CICPS.2015.7974074.

16. "PIC Microcontroller: Architecture and Its Applications," WatElectronics.com, 24-Sep-2019. [Online]. Available: https://www.watelectronics.com/pic-microcontroller-architecture-andapplications/. [Accessed: 21-Feb-2020]

17. "Payback Period." [Online]. Available: https://xplaind.com/849768/payback-period. [Accessed: 17-Feb-2020]. titled "Automatic Street Lighting using LDR and PIR sensor".

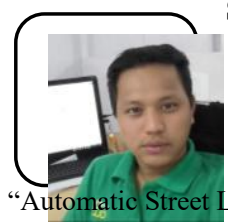

Sonam Tobgay is from Chhukha district, Bhutan. He studied Diploma in Electrical Engineering from Jigme Namgyel Engineering College in 2016. Currently he is working as Jr. Engineer (Electrical) at Samtse Distillery, Army Welfare Project Ltd. He was project group member for the student final year project titled ighting using LDR and PIR sensor".

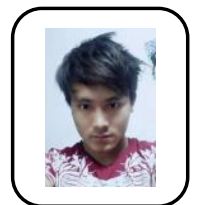

Dorji Gyeltshen was final year student in diploma in Electrical Engineering Department. Currently he is serving as instructor in Jigme Wangchuk Power Training Institute. He was project group member for the student final year project titled "Automatic Street Lighting using LDR and PIR sensor".

\section{AUTHORS PROFILE}

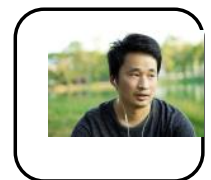

Karchung was born in Jamkhar, Trashiyangtse, Bhutan. He completed Bachelor of Engineering (B.E) in Electrical Engineering from College of science and Technology, Royal University of Bhutan and Master of Engineering (M.E) in Electrical Engineering from Naresuan University, Thailand in 2015 and 2020; respectively. He is currently working as Lecturer in Electrical Engineering Department at Jigme Namgyel Engineering College; Royal University of Bhutan, Bhutan. His expertise includes modeling of runoff-type hydropower plants, Micro Grid, Electrical Machine design and analysis, power electronics and control of electrical machines. His current research includes: sensorless vector control of induction motor, development of electric bicycle to suite in Bhutanese landscape, and variable frequency drives. His area of interest includes electrical machines and drives, power electronics, control system and Finite Element Analysis. He has numerous papers published in renowned international journals in the field of Modeling, simulation and analysis of electrical machines and drives and hydropower.

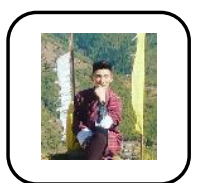

Zepa Tenzin is from Trashigang, Eastern Bhutan. He pursued Diploma in Electrical Engineering from Jigme Namgyel Engineering College, Royal University of Bhutan. He is currently studying Diploma in Automotive Mechanics in Sheffield College in Adelaide, Southern Australia. His interest includes electrical and mechanical systems. He also wishes to study Bachelors of Engineering in Electrical Engineering from same University. He was project group leader for the student final year project titled "Automatic Street Lighting using LDR and PIR sensor".

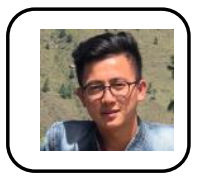

Sonam Tenzin is born was final year student in Diploma in Electrical Engineering Department. He was project group member for the student final year project

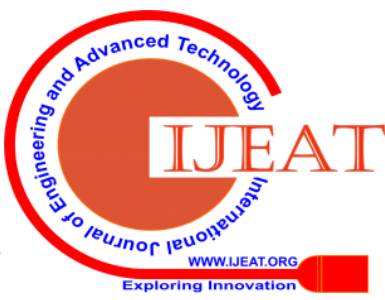

